\section{BRAZIULIAN JOURNAL \\ OF MEDICAL AND BIOLOGICAL RESEARCH}

www.bjournal.com.br
ISSN 1414-431X

Volume 45 (12) 1102-1340 December 2012

\section{BIOMIDICAL SCIENCES}

AND

CLINICAL INVESTIGATION

Braz J Med Biol Res, December 2012, Volume 45(12) 1269-1275

doi: 10.1590/S0100-879X2012007500141

Genetic and environmental influences on blood pressure and physical activity: a study of nuclear families from Muzambinho, Brazil

C.L.M. Forjaz, T. Bartholomeu, J.A.S. Rezende, J.A. Oliveira, L. Basso, G. Tani, A. Prista and J.A.R. Maia

The Brazilian Journal of Medical and Biological Research is partially financed by
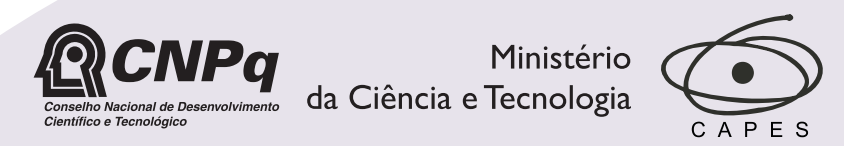

Ministério da Educação
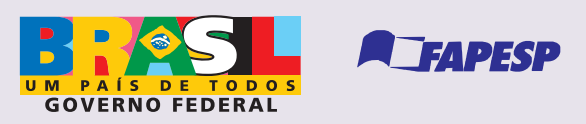

$$
\text { Institutional Sponsors }
$$
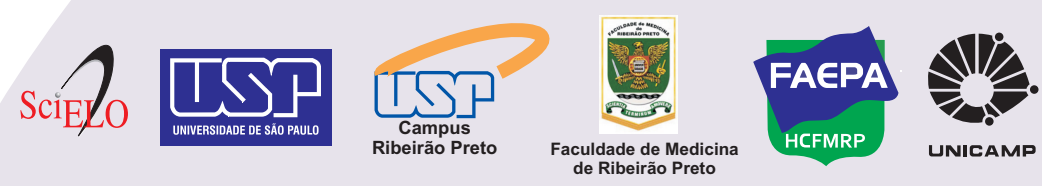

$\oplus$ SHIMADZu

UNICAMP
DFAPESP

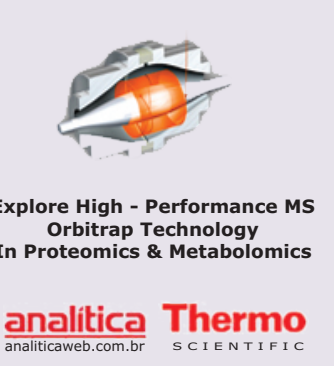




\title{
Genetic and environmental influences on blood pressure and physical activity: a study of nuclear families from Muzambinho, Brazil
}

\author{
C.L.M. Forjaz¹, T. Bartholomeu ${ }^{1}$, J.A.S. Rezende ${ }^{3}$, J.A. Oliveira², L. Basso², \\ G. Tani ${ }^{2}$, A. Prista ${ }^{4}$ and J.A.R. Maia ${ }^{5}$ \\ ${ }^{1}$ Laboratório de Hemodinâmica da Atividade Motora (LAHAM), \\ Escola de Educação Física e Esporte, Universidade de São Paulo, São Paulo, SP, Brasil \\ 2Laboratório de Comportamento Motor (LACOM), Escola de Educação Física e Esporte, \\ Universidade de São Paulo, São Paulo, SP, Brasil \\ ${ }^{3}$ Escola Superior de Educação Física de Muzambinho, Muzambinho, MG, Brasil \\ ${ }^{4}$ Faculdade de Educação Física e Desporto, Universidade Pedagógica, Maputo, Moçambique \\ ${ }^{5} \mathrm{CIFI} 2 \mathrm{D}$, Laboratório de Cineantropometria e Gabinete de Estatística Aplicada, \\ Faculdade de Desporto, Universidade do Porto, Porto, Portugal
}

\begin{abstract}
Blood pressure (BP) and physical activity (PA) levels are inversely associated. Since genetic factors account for the observed variation in each of these traits, it is possible that part of their association may be related to common genetic and/ or environmental influences. Thus, this study was designed to estimate the genetic and environmental correlations of BP and PA phenotypes in nuclear families from Muzambinho, Brazil. Families including 236 offspring (6 to 24 years) and their 82 fathers and 122 mothers (24 to 65 years) were evaluated. BP was measured, and total PA (TPA) was assessed by an interview (commuting, occupational, leisure time, and school time PA). Quantitative genetic modeling was used to estimate maximal heritability $\left(\mathrm{h}^{2}\right)$, and genetic and environmental correlations. Heritability was significant for all phenotypes (systolic BP: $h^{2}=0.37 \pm 0.10, P<0.05$; diastolic BP: $h^{2}=0.39 \pm 0.09, P<0.05 ;$ TPA: $\left.h^{2}=0.24 \pm 0.09, P<0.05\right)$. Significant genetic $\left(r_{g}\right)$ and environmental $\left(r_{e}\right)$ correlations were detected between systolic and diastolic BP $\left(r_{g}=0.67 \pm 0.12\right.$ and $r_{e}=0.48 \pm$ $0.08, P<0.05)$. Genetic correlations between BP and TPA were not significant, while a tendency to an environmental crosstrait correlation was found between diastolic BP and TPA $\left(r_{e}=-0.18 \pm 0.09, P=0.057\right)$. In conclusion, BP and PA are under genetic influences. Systolic and diastolic BP share common genes and environmental influences. Diastolic BP and TPA are probably under similar environmental influences.
\end{abstract}

Key words: Exercise; Hypertension; Environmental influence; Heritability; Genetic epidemiology

\section{Introduction}

Epidemiological data have shown an inverse relationship between regular physical activity (PA) and blood pressure (BP) $(1,2)$. Vigorous leisure time PA is recognized to reduce by $30 \%$ the risk of becoming hypertensive $(1,2)$. However, the linking agents of this association are not completely understood and may be due, in part, to common environmental and genetic factors.

Individually taken, PA and BP levels have been shown to be influenced by genetic as well as by environmental factors (3-7). The magnitude of genetic influences on these phenotypes varies. Previous review articles have shown that heritability $\left(\mathrm{h}^{2}\right.$ - the fraction of the total phenotypic variance that is accounted for by genetic factors) for systolic (SBP) and diastolic BP (DBP) ranged from 14 to 68 and from 6 to $62 \%$, respectively (7), while for $P A$, heritability ranged from 6 to $62 \%$ (6). The main explanations for this wide variation are differences in population structures in genetic and environmental terms, sample sizes, experimental designs, estimation techniques for $\mathrm{h}^{2}$, and phenotype assessment techniques $(6,7)$.

On the basis of these considerations, we hypothesized that the association between PA and BP may be due to

Correspondence: C.L.M. Forjaz, Av. Prof. Mello Moraes, 65, 05508-030 São Paulo, SP, Brasil. Fax: +55-11-3813-5921.

E-mail: cforjaz@usp.br

Received March 10, 2012. Accepted August 22, 2012. Available online September 7, 2012. Published December 17, 2012. 
common genetic influences, i.e., a pleiotropic effect, and/ or to common environmental influences. If this association can be identified, it offers a potential target for more efficient and effective strategies for reducing cardiovascular risk and for detecting genes and environmental factors, as well as their possible interaction, related to these two phenotypes.

Family studies provide a suitable design to investigate genetic and environmental influences not only on the variation of individual traits, but also on their covariation (8). We were able to identify only one study (4) that addressed this question, and concluded that variability of DBP in adulthood was significantly correlated to subjectively reported physical exercise done in adolescence (genetic, $r_{g}=-0.27$ and environment, $\left.r_{e}=-0.18\right)$, but not with aerobic exercise intensity during the entire lifetime. However, the study reported in Ref. 4 was conducted with twins and included only males, which limited generalization of results $(9,10)$. Moreover, only adults over 40 years old were included, which might have weakened the results obtained, since it is known that heritability of many health-related phenotypes, such as BP, decreases with aging (11).

Therefore, the purpose of the present study was to estimate the genetic and environmental correlations of BP and PA phenotypes in nuclear families that consist of two generations: parents and offspring. We investigated SBP and DBP phenotypes, as well as total PA (TPA).

\section{Material and Methods}

A volunteer sample of families was recruited from the 10-year-old students who participated in a larger study about growth, maturation, and motor development in Muzambinho (12). The study was approved by the Ethics Committee of Escola de Educação Física e Esporte, Universidade de São Paulo, and written informed consent was obtained from all of the participants. Data were collected between March 2008 and November 2009.

Muzambinho is a small town in the State of Minas Gerais, Brazil, with 19,925 inhabitants in 2007, 5650 of whom are between 5 and 19 years old (13). Its human developmental index is 0.801 , and its economy is based on agriculture, livestock, and handicrafts (14).

A total of 210 families were invited to participate, and data were assessed in 138. The two-generation family ranged in size from 3 to 9 subjects, and most of them consisted of $3(41 \%)$ or $4(41 \%)$ members. In some families, mothers and especially fathers did not come for evaluation, and thus the final sample consisted of 82 fathers, 122 mothers, and 236 offspring ( 126 sons and 110 daughters). Offspring age ranged from 6 to 24 years and parents' age ranged from 24 to 65 years. Missing values analysis was carried out using SYSTAT 13 (USA) within family structure and missing data distribution was carried out at random, which is essential for the analysis in the present study.
Weight $(\mathrm{kg})$ and height $(\mathrm{m})$ were measured with an electronic scale (Filizola, Brazil) following standard procedures and body mass index (BMI) was calculated [weight (kg) / height $(\mathrm{m})^{2}$ ]. Adults were classified as normal if BMI was $\leq 24.9 \mathrm{~kg} / \mathrm{m}^{2}$, as at risk of overweight if $25 \leq \mathrm{BMI} \leq 29.9 \mathrm{~kg} /$ $\mathrm{m}^{2}$, and as overweight if $\mathrm{BMI} \geq 30 \mathrm{~kg} / \mathrm{m}^{2}(15)$. In children and adolescents, classification was based on CDC centile growth charts, employing BMI <85th percentile as normal, BMI between the 85th and the 95th percentile for the age as overweight, and BMI >95th percentile for the age as obese (16).

BP was measured according to current guidelines (17) with the auscultatory method and aneroid sphygmomanometers. Calibrations were carried out daily. In both adults and youths, phases I and V of the Korotkoff's sound were employed for determining SBP and DBP, respectively. Five different cuff sizes were available, and the most adequate was chosen according to the subject's arm circumference. BP measurements were made at the same time of day in all of the volunteers, between 7:00 and 9:00 pm, avoiding any possible influence of circadian BP variation. BP was measured at least twice, and the average value was calculated. Anti-hypertensive treatment was assessed. Classifications of BP followed the specific criteria for youth and adults (18).

PA was assessed with a specific and culturally meaningful structured direct interview. Family members were all interviewed by the same team member. Main questions regarded their usually commuting PA (how do they move from one place to another: walking, cycling, etc.), occupational PA (what do they do for work: domestic chores, rural tasks, deliveries, etc.), and leisure time PA (what do they do during leisure time: cycling, soccer, swimming, gym classes, ballet, physical play games, e.g., tag, hide and seek, hopscotch, skip rope, and others). In addition, children were asked about their PA at school (including physical education classes and class intervals). Weekly frequency and duration were assessed for each type of PA. Their product was calculated to generate the weekly volume for each type of PA (min/week), and a TPA volume was obtained by their unweighted sum.

\section{Statistical analysis}

Descriptive analysis was done using SPSS. The independent $t$-test or Mann-Whitney test was used for comparisons between genders. PEDSTATS (19) was employed for pedigree checks. Phenotypes were adjusted for gender, age, gender $x$ age, age $^{2}$, gender $x$ age $^{2}$, and BP phenotypes were also adjusted to height or BMI and use of medication. These residuals were normalized and used to compute familial intrapair correlations for each trait as well as cross-traits using the S.A.G.E. 6.x software (Statistical Analysis for Genetic Epidemiology, Release 6.3, http://darwin.cwru.edu/, Case Western Reserve University, USA). Maximum likelihood estimates of heritability, genetic, and environmental correlations 
were computed using the SOLAR 4.0 software (Sequential Oligogenic Linkage Analysis Routines, http://www.sfbr.org, Southwest Foundation for Biomedical Research, USA). The heritability of a trait is the proportion of phenotypic variation $\left(\sigma_{p}{ }^{2}\right)$ that is accounted for by additive genetic effects $\left(\sigma_{g}{ }^{2}\right)$, and is given by $h^{2}=\left(\sigma_{g}{ }^{2}\right) /\left(\sigma_{p}{ }^{2}\right)$. In nuclear family studies without any additional information, only maximal heritability can be estimated, which means the sum of shared genetic and family environmental factors. A bivariate extension of the univariate quantitative genetic procedure, based on the suggestions of Falconer (20) and extended by Almasy et al. (21), was used to partition the phenotypic relationships $\left(r_{p}\right)$ between two traits into estimate genetic $\left(r_{g}\right)$ and environmental $\left(r_{e}\right)$ correlations between SBP/DBP, SBP/TPA, and DBP/TPA given by $r_{p}=r_{g} \sqrt{ } h^{2}{ }_{1} \sqrt{ } h^{2}{ }_{2}+r_{e} \sqrt{ }\left(1-h^{2}{ }_{1}\right) \sqrt{ }\left(1-h^{2}{ }_{2}\right)$. The significance of $h^{2}$ was determined using the likelihood ratio test by comparing the log-likelihood of a model where $\mathrm{h}^{2}$ was estimated against a model where $h^{2}$ was fixed at zero. A $P$ value $\leq 0.05$ was considered to be statistically significant.

\section{Results}

The characteristics of the family's members are described in Table 1. Based on the guidelines of the Joint National Committee on Prevention, Detection, Evaluation, and Treatment of High Blood Pressure (18), $24.4 \%$ of the parents, and $9.7 \%(\mathrm{~N}=23)$ of the offspring had BP levels higher than normal (either borderline or high). Eleven sub- jects were receiving anti-hypertensive medications at the time of assessment. Considering a minimum of $150 \mathrm{~min} /$ week of PA for adults, and $300 \mathrm{~min} /$ week of PA for children (22), $95.3 \%$ of the parents and $91.5 \%$ of the offspring were classified as active (Table 1).

Fathers were significantly older, heavier, taller, and had higher BP levels than mothers. However, both parents had similar TPAlevels (Table 1). No differences in anthropometric data or BP were found between male and female youths, while sons had higher levels of TPA than daughters.

The correlations between pairs of family members are shown in Table 2. For SBP, values ranged from -0.11 to 0.36 , and were significant for parent-offspring and siblings. For DBP, correlations ranged from 0.21 to 0.25 , and were significant for parent-offspring, siblings, and father-mother. For TPA, correlations ranged from 0.12 to 0.39 , and were significant for siblings and father-mother.

The heritabilities of each phenotype are shown in Table 3. All were statistically significant and ranged from 0.24 (TPA) to 0.39 (DBP). Similar results were obtained even when excluding from the analysis all subjects with hypertensive medication.

Genetic and environmental cross-trait correlations between SBP, DBP, and TPA are shown in Table 4. Genetic cross-trait correlations were significant only between SBP and DBP, while environmental correlations were significant between SBP and DBP and presented a strong tendency to significance between DBP and TPA $(P=0.057)$.

Table 1. Descriptive information (means \pm SD and risk prevalence) about family members.

\begin{tabular}{lcccc}
\hline & Fathers $(\mathrm{N}=82)$ & Mothers $(\mathrm{N}=122)$ & Sons $(\mathrm{N}=126)$ & Daughters $(\mathrm{N}=110)$ \\
\hline Age (years) & $40.2 \pm 7.2$ & $35.3 \pm 5.5^{*}$ & $11.2 \pm 3.3$ & $11.1 \pm 2.8$ \\
Weight (kg) & $74.5 \pm 11.8$ & $64.1 \pm 11.8^{*}$ & $39.1 \pm 14.6$ & $38.3 \pm 11.8$ \\
Height (cm) & $170 \pm 7$ & $158 \pm 6^{*}$ & $144 \pm 16$ & $141 \pm 14$ \\
BMI (kg/m $)$ & $25.7 \pm 3.4$ & $25.7 \pm 4.6$ & $18.3 \pm 3.5$ & $18.6 \pm 3.8$ \\
Systolic BP (mmHg) & $119 \pm 14$ & $113 \pm 17^{*}$ & $96 \pm 13$ & $96 \pm 12$ \\
Diastolic BP (mmHg) & $79 \pm 12$ & $75 \pm 12^{*}$ & $59 \pm 10$ & $61 \pm 11$ \\
TPA (min/week) & $1996 \pm 935$ & $1994 \pm 1062$ & $1312 \pm 961$ & $998 \pm 695^{*}$ \\
BMI classification & & & & \\
$\quad$ Normal (\%) & 41.5 & 50.0 & 78.6 & 80.9 \\
Risk of overweight (\%) & 51.2 & 34.2 & 14.3 & 7.3 \\
Overweight (\%) & 7.3 & 15.8 & 7.1 & 89.1 \\
BP classification & & & & 5.5 \\
$\quad$ Normal (\%) & 64.6 & 83.2 & 91.3 & 5.5 \\
Borderline (\%) & 18.3 & 4.2 & 2.4 & 8.4 \\
$\quad$ High (\%) & 17.1 & 12.6 & 6.3 & 91.6 \\
TPA classification & & & & \\
$\quad$ Insufficiently active (\%) & 4.9 & 4.4 & 8.7 & \\
$\quad$ Active (\%) & 95.1 & 95.6 & 91.3 & \\
\hline
\end{tabular}

$\mathrm{BMI}=$ body mass index; $\mathrm{BP}=$ blood pressure; TPA = total physical activity. ${ }^{*} \mathrm{P}<0.05$ compared to males of the same generation (Student $t$-test). 
Table 2. Phenotypic correlations between different pairs of family members considering their clustering effects.

\begin{tabular}{lccl}
\hline & \multicolumn{1}{c}{ SBPa } & DBPb & \multicolumn{1}{c}{ TPA $^{\mathrm{c}}$} \\
\hline Father-mother & $-0.113 \pm 0.124(0.3740)$ & $0.241 \pm 0.119^{*}(0.0500)$ & $0.393 \pm 0.001^{*}(0.0006)$ \\
Parent-offspring & $0.171 \pm 0.058^{*}(0.0039)$ & $0.251 \pm 0.059^{*}(0.0000)$ & $0.115 \pm 0.069(0.0991)$ \\
Siblings & $0.355 \pm 0.097^{*}(0.0008)$ & $0.209 \pm 0.101^{*}(0.0457)$ & $0.335 \pm 0.098^{*}(0.0016)$ \\
\hline
\end{tabular}

Data are reported as estimate $\pm \mathrm{SE}$ with $\mathrm{P}$ values in parentheses. $\mathrm{SBP}=$ systolic blood pressure; $\mathrm{DBP}=$

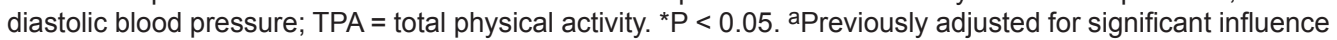
of age, gender, gender $x$ age $^{2}$, height, and drug. bPreviously adjusted for significant influence of age, gender, gender $\mathrm{x} \mathrm{age}^{2}$, height, and drug. 'Previously adjusted for significant influence of age, and gender $\mathrm{x}$ age.

Table 3. Maximal heritability ( $h^{2}$; estimate \pm SE) of systolic blood pressure (SBP), diastolic blood pressure (DBP), and total physical activity (TPA).

\begin{tabular}{lcclc}
\hline Phenotype & $\mathrm{h}^{2}$ & $\mathrm{P}$ & \multicolumn{1}{c}{ Covariates } & $\begin{array}{c}\text { Proportion of variance } \\
\text { explained by covariates }\end{array}$ \\
\hline SBP & $0.37 \pm 0.10<0.01$ & Age, gender, gender $\mathrm{x} \mathrm{agge}^{2}$, height, drug & 0.48 \\
DBP & $0.39 \pm 0.09<0.01$ & Age, gender, gender $\mathrm{x} \mathrm{age}^{2}$, height, drug & 0.46 \\
TPA & $0.24 \pm 0.09<0.01$ & Age, gender $x$ age & 0.15 \\
\hline
\end{tabular}

Table 4. Genetic and environmental correlations (estimate \pm SE) obtained between systolic blood pressure (SBP), diastolic blood pressure (DBP) and total physical activity (TPA).

\begin{tabular}{|c|c|c|c|c|c|c|}
\hline & \multicolumn{3}{|c|}{ Genetic correlations } & \multicolumn{3}{|c|}{ Environmental correlations } \\
\hline & SBP & DBP & TPA & SBP & DBP & TPA \\
\hline SBP & - & & & - & & \\
\hline DBP & $0.67 \pm 0.12^{*}$ & - & & $0.48 \pm 0.08^{*}$ & - & \\
\hline TPA & $-0.08 \pm 0.24$ & $0.05 \pm 0.23$ & - & $-0.04 \pm 0.10$ & $-0.18 \pm 0.09^{+}$ & - \\
\hline
\end{tabular}

${ }^{*} \mathrm{P}<0.05,{ }^{+} \mathrm{P}=0.057$.

\section{Discussion}

The main findings of the present study were that: a) low, but significant genetic factors explained the variation of SBP and DBP, as well as TPA; b) SBP and DBP cross-trait genetic and environmental influences were significant; $c$ ) no such influences were evident for SBP and TPA, while a strong tendency $(P=0.057)$ to a significant cross-trait environmental correlation was observed between DBP and TPA.

The prevalence of high BP levels calculated in the present population based on international criteria (18) $(24 \%$ in adults and $10 \%$ in youths) was similar to that reported in previous studies (23-25). In contrast, reported PA levels classified $95 \%$ of the adults and $91 \%$ of the youths as active, a higher rate than previously reported (26-28). Such a high level of PA might be explained by sociocultural aspects, since in Muzambinho, occupational PA (mainly rural tasks for men and domestic chores for women) was reported by $89 \%$ of the adults, and leisure time PA, mainly street games was performed by $92 \%$ of the youths.

Moderate prevalence of high BP simultaneously with a high level of PA might seem odd, since an inverse relationship is expected between these factors $(1,2)$. However, this relationship may be influenced by physical fitness. Franks et al. (29) observed that PA was not inversely associated with metabolic factors when subjects had high cardiovascular fitness. Other factors, such as nutrition, might be more 
important in these cases.

Genetic factors explained 37 and $39 \%$ of SBP and DBP variation in the Muzambinho population. Similar values were reported in Chinese (30) and Brazilian (5) samples. Furthermore, genetic factors explained $24 \%$ of the variance in TPA, which is within the range of reported values for different PA phenotypes (6). However, the present heritability estimates differed from those obtained in the Baependi Heart Study $(31,32)$ that investigated another city from the same Brazilian state (26\% for SBP and DBP, and 11 to $35 \%$ for distinct PA indexes). Differences in study design (nuclear families vs extended families), sample characteristics (children and adults vs only adults), covariates used and ways to map PA may explain the differences.

The heritability indexes evaluated in the present study represent the upper-limit heritabilities (10). Nuclear families share not only genes but also a common environment, and without additional information, the heritability calculated for these families represents the sum of these influences. In this study, common environment should have had an important influence because correlations between father and mother were significant for DBP and TPA. Thus, the heritability index calculated probably overestimated the true genetic influence.

The main aim of this study was to analyze the cross-trait genetic and environmental correlations. As expected (3), these correlations were significant between SBP and DBP, which shows that these traits share common genes and environmental conditions. Nevertheless, the main novelty of the study was the analysis of genetic and environmental co-influences on BP and TPA. This analysis showed no pleiotropy between these traits $\left(r_{g}=-0.08\right.$ and $r_{g}=0.05$ SBP/TPA and DBP/TPA, respectively), which implies that they were under different genetic influences. In contrast, a tendency to a significant cross-trait environmental correlation was observed between $\operatorname{DBP}$ and TPA $\left(r_{e}=-0.18, P=0.057\right)$, strongly suggesting that these traits may share common environmental influences that had opposite effects on these phenotypes, increasing TPA and decreasing BP or vice versa.

The failure to detect a clear cross-trait correlation between TPA and DBP might be explained by the large age range of the offspring combined with the fact that familial resemblance for BP varies with age and may peak around age 30 , decreasing in younger family members $(33,34)$. Most of the offspring in the present study (64\%) were 8 to 12 years old. Thus, the observation of a tendency at this age may really represent an important influence.

The absence of pleiotropy between PA and BP is opposite to findings reported by Hernelahti et al. (4). However, in that study, correlation was observed between reported PA at adolescence and DBP measured at 40 years of age, and the estimated $r_{g}$ was low, $r=0.27$. In addition, similar to the present results, these authors did not observe any pleiotropic effect when other phenotype of PA was analyzed. Taken together, these results may suggest that common genetic influences on BP and PA may be linked to some chronological life-course events, namely different PA modalities, intensities, duration, and their associations with susceptibility genes that may evidence the presence of incomplete pleiotropy.

The present finding that TPA and DBP may be influenced by common environmental factors has important clinical implications since it gives scientific support to the search for environmental interventions that simultaneously increase PA levels and decreases BP, preventing hypertension. Nutritional factors may be a strong candidate for this influence since unhealthy nutrition is associated with higher BP levels (35) and lower PA $(36,37)$. In addition, a healthy diet has resulted in lower BP levels and higher PA levels (38).

Environmental cross-trait correlation was suggested between PA and DBP but not SBP. Exercise hypotensive effect is primarily related to an increase in vasodilatory capacity (39) that may result in a decrease in DBP and may also facilitate muscle metabolism, improving performance.

It may be argued that the sample size of the present study was not big enough to detect the pleiotropic effect. However, it was similar to previous reports (40), and represented $2.2 \%$ of the Muzambinho's population. Although antihypertensive use might be a confounding factor, only 11 parents were receiving these agents, and an analysis without them revealed similar results. Another caveat is the way PA was assessed. Since no previous knowledge of PA patterns of this population was available, a structured open interview was required. However, interviews are open to some degree of inaccuracy but were usually employed in previous studies (4). Finally, the Muzambinho population studied here was very active, which might limit extrapolation of the results to other samples. However, many small cities in Brazil preserve the old PA habits and deserve to be investigated. In this context, the present study highlighted an important issue by showing that even in these very active samples, cardiovascular risk is high, and some environmental factors may influence both PA and DBP.

In conclusion, SBP, DBP, and TPA were under significant genetic influences. SBP and DBP shared part of the genetic and environmental influences, while no pleiotropy was evident between BP and TPA. However, environmental influences on DBP and TPA may be similar.

\section{Acknowledgments}

The authors acknowledge the volunteers, school directors, and Muzambinho's Educational and Health Secretariat. We also thank students, teachers, and informatics technicians who helped with data collection and analysis. Research supported by CNPq (\#478249/2007-1), FAPESP (\#2009/18638-6), USP, CAPES-PROEX, and FCT (Portugal, PTDC/DES/67569/2006 and FCOMP-01-0124FEDEB-09608). 


\section{References}

1. Fagard RH. Physical activity, physical fitness and the incidence of hypertension. J Hypertens 2005; 23: 265-267.

2. Pescatello LS, Franklin BA, Fagard R, Farquhar WB, Kelley GA, Ray CA. American College of Sports Medicine position stand. Exercise and hypertension. Med Sci Sports Exerc 2004; 36: 533-553.

3. Cui J, Hopper JL, Harrap SB. Genes and family environment explain correlations between blood pressure and body mass index. Hypertension 2002; 40: 7-12.

4. Hernelahti M, Levalahti E, Simonen RL, Kaprio J, Kujala UM, Uusitalo-Koskinen AL, et al. Relative roles of heredity and physical activity in adolescence and adulthood on blood pressure. J Appl Physiol 2004; 97: 1046-1052.

5. Krieger H, Morton NE, Rao DC, Azevedo E. Familial determinants of blood pressure in northeastern Brazil. Hum Genet 1980; 53: 415-418.

6. Chaves RN, Souza MC, Santos D, Garganta R, Seabra A, Maia JAR. Agregação familiar nos níveis de atividade física: um resumo do estado da arte. Rev Bras Ativ Física Saúde 2010; 15: 19-26.

7. Fermino RC, Seabra A, Garganta R, Maia JAR. Genetic factors and variability in blood pressure: a brief literature review. Rev Bras Cineantropom Desempenho Hum 2009; 11: 341-349.

8. Lynch M, Walsh B. Genetics and analysis of quantitative traits. Sanderland: Sinauer Associates; 1998.

9. Bouchard C, Malina RM, Pérusse L. Genetics of fitness and physical performance. Champaign: Human Kinetics; 1997.

10. Burton PR, Tobin MD, Hopper JL. Key concepts in genetic epidemiology. Lancet 2005; 366: 941-951.

11. Chen W, Srinivasan SR, Bao W, Berenson GS. The magnitude of familial associations of cardiovascular risk factor variables between parents and offspring are influenced by age: the Bogalusa Heart Study. Ann Epidemiol 2001; 11: 522-528.

12. Basso L, Junior CM, Oliveira JA, Forjaz CLdM, Souza JAd, Prista $A$, et al. Crescimento e desenvolvimento motor de escolares de Muzambinho: um estudo com implicações acadêmicas, sociais e de política interinstitucional. Rev Port Cien Desp 2009; 9: 247-257.

13. Instituto Brasileiro de Geografia e Estatística. Censo da Educação Superior. Brasília: Instituto Brasileiro de Geografia e Estatística; 2007.

14. Instituto Brasileiro de Geografia e Estatística. Censo Populacional 2010. Brasília: Instituto Brasileiro de Geografia e Estatística; 2010.

15. World Health Organization. Diet, nutrition and the prevention of chronic diseases. Genebra: World Health Organization; 2003.

16. Kuczmarski RJ, Ogden CL, Guo SS, Grummer-Strawn LM, Flegal KM, Mei Z, et al. 2000 CDC Growth Charts for the United States: methods and development. Vital Health Stat 11 2002; 246: 1-190.

17. Williams JS, Brown SM, Conlin PR. Videos in clinical medicine. Blood-pressure measurement. N Engl J Med 2009; 360: e6.

18. Chobanian AV, Bakris GL, Black HR, Cushman WC, Green LA, Izzo JL Jr, et al. The Seventh Report of the Joint National Committee on Prevention, Detection, Evaluation, and Treat- ment of High Blood Pressure: the JNC 7 report. JAMA 2003; 289: 2560-2572.

19. Wigginton JE, Abecasis GR. PEDSTATS: descriptive statistics, graphics and quality assessment for gene mapping data. Bioinformatics 2005; 21: 3445-3447.

20. Falconer DS. Introduction to quantitative genetics. Harlow: Longman Scientific \& Technical; 2005.

21. Almasy L, Dyer TD, Blangero J. Bivariate quantitative trait linkage analysis: pleiotropy versus co-incident linkages. Genet Epidemiol 1997; 14: 953-958.

22. American College of Sports Medicine. ACSM's Guidelines for exercise testing and prescription. Philadelphia: Lippincott Williams \& Wilkins; 2010.

23. [IV Brazilian guidelines in arterial hypertension]. Arq Bras Cardiol 2004; 82 (Suppl 4): 7-22.

24. Candido AP, Benedetto R, Castro AP, Carmo JS, Nicolato $\mathrm{RL}$, Nascimento-Neto RM, et al. Cardiovascular risk factors in children and adolescents living in an urban area of Southeast of Brazil: Ouro Preto Study. Eur J Pediatr 2009; 168: 1373-1382.

25. Coronelli CL, de Moura EC. [Hypercholesterolemia and its risk factors among schoolchildren]. Rev Saúde Pública 2003; 37: 24-31.

26. Dumith SC. Physical activity in Brazil: a systematic review. Cad Saúde Pública 2009; 25 (Suppl 3): S415-S426.

27. Hallal PC, Bertoldi AD, Goncalves H, Victora CG. [Prevalence of sedentary lifestyle and associated factors in adolescents 10 to 12 years of age]. Cad Saúde Pública 2006; 22: $1277-1287$.

28. Silva MA, Rivera IR, Ferraz MR, Pinheiro AJ, Alves SW, Moura AA, et al. Prevalence of cardiovascular risk factors in child and adolescent students in the city of Maceió. Arq Bras Cardiol 2005; 84: 387-392.

29. Franks PW, Ekelund U, Brage S, Wong MY, Wareham NJ. Does the association of habitual physical activity with the metabolic syndrome differ by level of cardiorespiratory fitness? Diabetes Care 2004; 27: 1187-1193.

30. Gu D, Rice T, Wang S, Yang W, Gu C, Chen CS, et al. Heritability of blood pressure responses to dietary sodium and potassium intake in a Chinese population. Hypertension 2007; 50: 116-122.

31. Horimoto AR, Giolo SR, Oliveira CM, Alvim RO, Soler JP, de Andrade $\mathrm{M}$, et al. Heritability of physical activity traits in Brazilian families: the Baependi Heart Study. BMC Med Genet 2011; 12: 155-163.

32. de Oliveira CM, Pereira AC, de Andrade M, Soler JM, Krieger JE. Heritability of cardiovascular risk factors in a Brazilian population: Baependi Heart Study. BMC Med Genet 2008; 9: 32-39.

33. Province MA, Rao DC. A new model for the resolution of cultural and biological inheritance in the presence of temporal trends: application to systolic blood pressure. Genet Epidemiol 1985; 2: 363-374.

34. Province MA, Tishler P, Rao DC. Repeated-measures model for the investigation of temporal trends using longitudinal family studies: application to systolic blood pressure. Genet Epidemiol 1989; 6: 333-347.

35. Sacks FM, Svetkey LP, Vollmer WM, Appel LJ, Bray GA, Harsha D, et al. Effects on blood pressure of reduced dietary 
sodium and the Dietary Approaches to Stop Hypertension (DASH) diet. DASH-Sodium Collaborative Research Group. N Engl J Med 2001; 344: 3-10.

36. Cho ER, Shin A, Lim SY, Kim J. Dietary patterns and their associations with health behaviours in Korea. Public Health Nutr 2011; 14: 356-364.

37. Charreire H, Kesse-Guyot E, Bertrais S, Simon C, Chaix $\mathrm{B}$, Weber $\mathrm{C}$, et al. Associations between dietary patterns, physical activity (leisure-time and occupational) and television viewing in middle-aged French adults. Br J Nutr 2011; 105: 902-910.

38. Panunzio MF, Caporizzi R, Antoniciello A, Cela EP, Ferguson LR, D'Ambrosio P. Randomized, controlled nutrition education trial promotes a Mediterranean diet and improves anthropometric, dietary, and metabolic parameters in adults. Ann Ig 2011; 23: 13-25.

39. Cornelissen VA, Fagard RH. Effects of endurance training on blood pressure, blood pressure-regulating mechanisms, and cardiovascular risk factors. Hypertension 2005; 46: 667675.

40. An P, Rice T, Gagnon J, Borecki IB, Perusse L, Leon AS, et al. Familial aggregation of resting blood pressure and heart rate in a sedentary population: the HERITAGE Family Study. Health, Risk Factors, Exercise Training, and Genetics. Am J Hypertens 1999; 12: 264-270. 